Scrupulous attention to the wounds is given to prevent risk of infection. Heparin locking is performed at weekly intervals for the first month, at least monthly therafter, and after each sampling or transfusion.

In both babies the device was inserted without complication. The wounds healed well and there have been no infection related or other problems for a patient total of four years. Both children require top-up transfusions at intervals of four to six weeks to maintain adequate haemoglobin concentrations. These and any needle accessing must be performed using the special Huber point, non-coring needles (see figure). As the life of the silicon membrane of the port is said to be $\mathbf{2 0 0 0}$ punctures, some years of use can be anticipated. We perform radiography every four months to observe the position and condition of the systems as the children grow.

\section{Discussion}

The length of use of the subcutaneous systems, combined with the lack of restriction on lifestyle in otherwise healthy infants, allows their increasing use with great clinical advantage. ${ }^{2}$ Risk of infection is widely reported to be lower for the implanted devices than the subcutaneous tunnelled internal-external lines. ${ }^{3}$ We suggest that this applies particularly in infancy. Likewise thrombotic occlusion is less frequent ${ }^{4}$ and there is no risk of external fracture. Internal fracture can be anticipated by chest radiography and looking for the 'pinch-off' sign-that is, narrowing of the catheter at any point (usually between clavicle and first rib). If a catheter fragment should embolise it can be safely retrieved using cardiac catheterisation.

Blockage of the catheter can be treated with urokinase, and persistent withdrawal occlusion has also been shown to resolve with thrombolytic treatment when secondary to fibrin sheath formation on the catheter tip. ${ }^{56}$ If the catheter and port should separate, surgical remedy is usually required.

The lack of disruption of normal daily activi- ties after successful implantation is of special importance in children. We have noticed that family stresses are relieved; that is an important aspect of patient care. There is no percutaneous entry site requiring special care or dressing and the child can bathe once the wound has healed. Visits to the hospital are less of a strain because venous access is more readily assured. The onus on medical staff to obtain peripheral venous access in these chubby and otherwise extremely healthy infants is alleviated. Other reports also comment specifically on patient and parent approval and acceptance of these subcutaneous devices. ${ }^{4}$

Provided the physician is aware of the infrequent complications, we hold that insertion of implantable intravenous access devices in infants, who present long term problems, greatly enhances medical care provided for the baby and family. Further experience will show whether these systems provide complicationfree access in our patients until they are old enough for elective splenectomy to be considered. Experience thus far suggests that this is a safe and happy way to achieve long term intravenous access to assist in optimal management and promote normal development in growing babies.

We thank Professor L Luzatto for helpful advice at diagnosis, Dr G P Taylor for permission to describe patients under his care, and Mr C M Vickery for his surgical expertise.

1 Kondi ES, Pietrafitta JJ, Barriola JA. Technique for placement of a totally implantable venous access device. $\mathcal{F}$ Surg Oncol 1988;37:272-7.

2 Hockenberry MJ, Schultz WH, Bennett B, Bryant R, Falletta JM. Experience with minimal complications in implanted catheters in children. Am f Pediatr Hematol

3 McDowell HP, Hart CA, Martin J. Implantable subcutaneous venous catheters. Arch Dis Child 1986;61:1307-8.

4 Carde P, Cosset-Delaigue MF, Laplanche A, Chareau I. Carde P, Cosset-Delaigue MF, Laplanche A, Chareau I.
Classical external indwelling central venous catheter versus totally implanted venous access systems for chemotherapy administration; a randomised trial in 100 patients with solid tumours. European fournal of Cancer and Clinical Oncology 1989;25:939-44.

5 Bagnall HA, Gomperts E, Atkinson JB. Continuous infusion of low dose urokinase in the treatment of central venous catheter thrombosis in infants and children. Pediatrics 1989;83:963-6.

6 Tschirhart JM, Rao MK. Mechanism and management of persistent withdrawal occlusion. Am Surg 1988;54:326-8.

\title{
Paediatric psychotherapy: a service in a general outpatient clinic
}

\author{
Susan Vas Dias, Sheila A McKenzie
}

Department of
Paediatrics, Oldchurch
Hospital, Romford,
Essex RM7 0BE
Susan Vas Dias
Sheila A McKenzie
Correspondence to:
S Vas Dias.
Accepted 15 September 1991
(Arch Dis Child 1992;67:132-4)

\author{
Abstract \\ The service of paediatric psychotherapy to a \\ general paediatric outpatient clinic is de- \\ scribed. Using techniques developed to suit \\ paediatric patients a median of nine patients \\ each clinic were treated. Referral symptoms \\ resolved in a median time of four months after \\ a median of seven sessions. This model for \\ the management of paediatric patients with \\ emotional and behavioural difficulties may
}

allow an effective and efficient use of psychotherapy time.

Emotional and behaviour difficulties in children account for a large proportion of the problems seen in paediatric clinics, $28 \%$ in a recent report. ${ }^{1}$ After referral, further help may be sought from a child psychiatrist, psychotherapist, clinical psychologist, or social worker, often at 
another location such as the child guidance clinic and inevitably with further delay. Poor integration of paediatric and psychiatric services and difficulties in communication between them have been highlighted. ${ }^{2}$ It would appear then that a service delivered directly to a general clinic could have many advantages. The benefits of liaison child psychiatry and psychotherapy and its multidisciplinary team approach to specialist paediatric units have been well described elsewhere. ${ }^{3-5}$

This report describes a paediatric psychotherapy service delivered directly to a general paediatric outpatient clinic. This complements the existing child guidance and child psychiatric services to hospital and community. The goal was to discover if it was possible to deliver an effective and efficient service in terms of improvement in referral symptoms and throughput.

\section{Methods}

Children were referred from general practitioners, house staff, nurses, and health visitors. The waiting space was shared with two adult clinics. The clinic ran from approximately $1 \mathrm{pm}$ until $6 \mathrm{pm}$ to allow attendance outside school hours if appropriate, to accommodate varying consultation times, and to allow a throughput which would facilitate frequent visits and thus keep up the momentum of treatment.

A consultant paediatrician supervised the management of any physical disorders which existed. When no organic disease was identified, the child and family were reassured. During both appraisal and treatment the paediatrician used, where appropriate, behavioural techniques such as the preparation of star charts, diaries, and task direction for the establishment of routines such as bedtime and mealtimes.

When it was felt that the emotional complexities of a child's or family's difficulties were such that behavioural techniques were not appropriate or needed complementing, the family was prepared for referral to the psychotherapist, who worked in a neighbouring room. An introduction was made during the same meeting and an appointment given, usually for the next week. Thereafter children with both physical and emotional components to their symptoms, for example, soiling, made one visit for two appointments.

The psychotherapist's methods are discussed

Referrals in $1988-90$

\begin{tabular}{lll}
\hline $\begin{array}{l}\text { Reason for } \\
\text { referral }\end{array}$ & $\begin{array}{l}\text { Referrals to } \\
\text { paediatrician }\end{array}$ & $\begin{array}{l}\text { Referrals from } \\
\text { peediatrician } \\
\text { to psychotherapist }\end{array}$ \\
\hline Soiling & 63 & 14 \\
Sleep disturbance & 32 & 1 \\
Eating disorders & 27 & 8 \\
Abdominal pain & 24 & 6 \\
Eneuresis & 26 & 4 \\
Conduct disturbance & 25 & 23 \\
Headaches & 13 & 4 \\
Bereavement (excluding & 14 & 4 \\
SIDS and perinatal death) & 45 & 30 \\
Othert & 269 & 94 \\
Total & & 9 \\
\hline
\end{tabular}

*SIDS=sudden infant death syndrome.

†Includes anxiety, chronic illness, adolescent difficulties, non-compliance with drug treatments. elsewhere ${ }^{6}$ but in summary involved working with the child individually as well as with his/her family. The approach did not use tests or questionnaires but relied on what the child and family communicated through play, talking, silence, expression of feelings-especially anger-and the relationship that developed between therapist and child and family. Early on families may have been asked to prepare a 'concern' diary. This involved the parents noting down each day, on average for a fortnight, everything that concerned them in relation to the child, for example, the events leading up to and around undesirable behaviour. This served a number of purposes, for example, to see if there was a pattern of anxiety that manifested itself in maladaptive ways and to encourage a feeling of active parental involvement.

Each child was seen invidually, usually once a week or once every two weeks, for 20-35 minutes each time. As the need arose the meetings also included the parents and siblings or the parents on their own. Children with life threatening illnesses such as anorexia nervosa, severe depression, autism, or who needed complex family systems work, were referred to complementary services. Consultations and visits to schools and liaison with social services were undertaken as necessary.

\section{Results}

Between 1988 and 1990, 269 children with difficulties which may have had either emotional or behavioural contributing factors were referred to the consultant paediatrician. The table shows that the pattern of referral symptoms to the paediatrician was different from that of the paediatrician to the psychotherapist suggesting that the more task oriented behavioural approach of the paediatrician was successful in the treatment of some problems, for example, sleep disturbance, than others, for example, conduct disturbance. Fourteen referrals from other sources made a total of 108 to the psychotherapist. Thirteen did not attend after the first introduction, nine dropped out of treatment, 18 continued into 1991, and three returned after discharge. Thus 68 completed treatment. Fifty seven were discharged with referral symptoms resolved, four discharged without improvement, and seven were referred elsewhere.

There were 83 clinics and the median number of patients/clinic was nine (range 3-13) and the median age was eight years (range 1-17). The median length of completed treatment was four months (range 1-24). The median number of sessions per patient was seven (range 1-72). Five patients were in treatment for two to three years.

\section{Discussion}

One advantage of a parallel service is that families attend only one clinic where they have two appointments. Waiting time for an appointment with any of the child psychological services is eliminated. The setting may be less 
threatening for both the uptake and carrying through of treatment. The waiting area accommodates adults and children for other clinics. Perhaps this allows the psychotherapist to be seen as part of a team and removes some of the mystique and stigma often associated with referral for treatment of emotional or behavioural problems.

A very reasonable criticism of psychotherapy is that treatment is frequent and lengthy. The experience in the clinic suggests that there are a number of children who may benefit from short term treatment, thus making it available to more children. Psychotherapy does not lend itself easily to clinical trials. It would be difficult to compare this model with other approaches to discover whether it is as effective in terms of throughput and outcome. The only outcome described here is the resolution of referral symptoms at the time of discharge and we recognise that this has not been evaluated objectively. Nevertheless this parallel service would seem to address some of the problems of referring children with emotional and behaviour problems for help. ${ }^{2}$ The experience has also been of educational value, not only in the development of short term psychotherapeutic techniques, ${ }^{6}$ but also in the training of medical staff in the different ways to listen to how children and families communicate their concerns and the ways in which to work with them.

1 Garralda ME, Bailey D. Psychiatric disorders in general paediatric practice. Arch Dis Child 1989;64:1727-33.

Oke S, Moyer R. Referrals to child psychiatry-a survey of staff attitudes. Arch Dis Child 1991;66:862-5.

3 Josse JD, Challener J. Liaison psychotherapy in a hospital paediatric diabetic clinic. Arch Dis Child 1987:62:518-22. Vas Dias S. Psychotherapy in special care baby units. Nursing Times 1987;83:50-2.

5 Black D, McFadyen A, Broster G. Development of a psychiatric liaison service. Arch Dis Child 1990;65:1373-5.

6 Vas Dias S. Paediatric psychotherapy: the development of a techique for a service in a general out-patient clinic. Fournal of Child Psychotherapy 1990;16:7-20.

\title{
Coeliac disease and lymphangiectasia
}

\author{
Vojislav N Perisic, George Kokai
}

Mother and Child Health

Institute of Serbia,

Radoja Dakica 6-8, 11070 Novi Beograd,

Yugoslavia

Vojislav N Perisic

George Kokai

Correspondence to: Dr Perisic.

Accepted 28 August 1991

(Arch Dis Child 1992;67:134-6)

\begin{abstract}
Two out of 74 children with coeliac disease demonstrated severe intestinal protein loss. In both children a serial small bowel biopsy specimen showed intestinal lymphangiectasia to be also present. Intestinal lymphangiectasia is another disorder that may be associated with coeliac disease.
\end{abstract}

Several disorders have been found to occur in association with coeliac disease. Cystic fibrosis, ulcerative colitis, Crohn's disease, collagenous colitis, giardiasis, and recurrent oral and small intestinal ulceration have all been reported in children and adults with coeliac disease. ${ }^{12}$ However, the coexistence of coeliac disease with intestinal lymphangiectasia has not so far been described. Both diseases may present with substantial enteric protein loss and steatorrhoea and potentially mimic each other, although the dis- tinctive small intestinal mucosal changes will discriminate between the two.

We describe for the first time coeliac disease and intestinal lymphangiectasia occurring together in two children with severe enteric protein loss.

\section{Patients and methods}

Between May 1981 and December 1985, 74 children were diagnosed as having coeliac disease according to the criteria of the European Society of Paediatric Gastroenterology and Nutrition. ${ }^{3}$ In addition to chronic diarrhoea, failure to thrive, and steatorrhoea two of the children also had clinical and laboratory evidence of severe intestinal protein loss (table). ${ }^{4}$ Case 1 also developed the clinical features of tuberous sclerosis: fibroangiomatous naevi, adenoma sebaceum, and brain tubers on computed tomography at the age of $7 \cdot 5$ years.

In both children small intestinal mucosal biopsy specimens demonstrated either total or subtotal villous atrophy with other microscopic features commonly seen in coeliac disease: crypt hyperplasia, increased number of intraepithelial lymphocytes, heavy lymphoplasmocytic infiltration of the lamina propria, and appreciable lymphangiectasia (fig $1 \mathrm{~A}$ and $2 \mathrm{~A}$ ). Sweat chloride concentration, stool chromatography for sugars, duodenal juice and stool microscopy for parasites, liver function tests, urinalysis, and chest radiography were all normal or negative. Concentration of coagulation factors II and VII were decreased and returned to normal after parenteral administration of vitamin $\mathrm{K}$. Both children initially demonstrated a complete absence of serum IgA and IgM. Case 1 had a low IgG concentration of $1.9 \mathrm{~g} / 1$ (normal range $7.62(2.09) \mathrm{g} / \mathrm{l})$. Case 2 also had a decreased IgG concentration of $1.6 \mathrm{~g} / \mathrm{l}$ (normal range $6 \cdot 61(2 \cdot 19) \mathrm{g} / \mathrm{l})$. Examination of peripheral

Details of the two patients with coeliac disease and lymphangiectasia

\begin{tabular}{llllll}
\hline $\begin{array}{l}\text { Case Sex } \\
\text { No }\end{array}$ & $\begin{array}{l}\text { Age } \\
\text { (months) }\end{array}$ & Oedema & $\begin{array}{l}\text { Serum } \\
\text { albumin } \\
(\mathrm{g} / \mathrm{l})\end{array}$ & $\begin{array}{l}\text { Faecal fat } \\
(\mathrm{g} / 100 \\
\text { stool })\end{array}$ \\
\hline 1 & $\mathrm{~F}$ & 25 & Generalised & 10 & $\begin{array}{l}68 \cdot 4 \\
\text { Legs and eyelids }\end{array}$ \\
\hline & $\mathrm{M}$ & 12 & 18 & $55 \cdot 8$ \\
\hline
\end{tabular}

*Three day collection. 